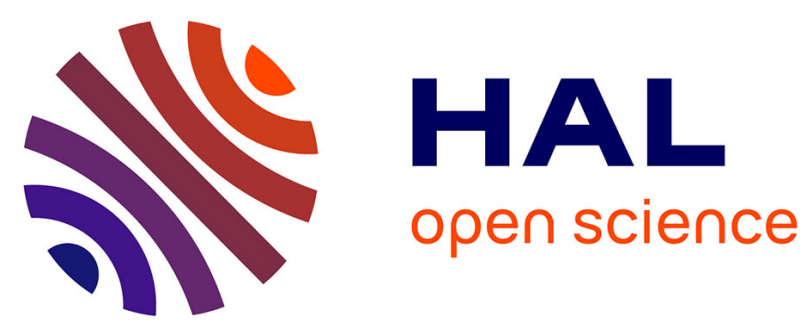

\title{
Means of Using Cyclic Voltammetry to Rapidly Design a Stable DMC-Based Electrolyte for Na-Ion Batteries
}

Claudio Cometto, Guochun Yan, Sathiya Mariyappan, Jean-marie Tarascon

\section{To cite this version:}

Claudio Cometto, Guochun Yan, Sathiya Mariyappan, Jean-marie Tarascon. Means of Using Cyclic Voltammetry to Rapidly Design a Stable DMC-Based Electrolyte for Na-Ion Batteries. Journal of The Electrochemical Society, 2019, 166 (15), pp.3723 - 3730. 10.1149/2.0721915jes . hal-02402427

\section{HAL Id: hal-02402427 https://hal.sorbonne-universite.fr/hal-02402427}

Submitted on 10 Dec 2019

HAL is a multi-disciplinary open access archive for the deposit and dissemination of scientific research documents, whether they are published or not. The documents may come from teaching and research institutions in France or abroad, or from public or private research centers.
L'archive ouverte pluridisciplinaire HAL, est destinée au dépôt et à la diffusion de documents scientifiques de niveau recherche, publiés ou non, émanant des établissements d'enseignement et de recherche français ou étrangers, des laboratoires publics ou privés. 


\title{
Means of Using Cyclic Voltammetry to Rapidly Design a Stable DMC-Based Electrolyte for Na-Ion Batteries
}

\author{
Claudio Cometto, $\oplus^{1,2}$ Guochun Yan, ${ }^{1,2}$ Sathiya Mariyappan, ${ }^{1,2}$ \\ and Jean-Marie Tarascon $\oplus^{1,2,3, \mathrm{z}}$ \\ ${ }^{1}$ Chimie du Solide-Energie, UMR 8260, Collège de France, 75231 Paris Cedex 05, France \\ ${ }^{2}$ Réseau sur le Stockage Electrochimique de l’Energie (RS2E), FR CNRS 3459, Amiens 80039, France \\ ${ }^{3}$ Sorbonne Université, CNRS, 75005 Paris, France
}

\begin{abstract}
Na-ion batteries are standing as a serious contender to the Li-ion technology for mass storage applications provided we fully master their chemistry, among which the electrolyte is of paramount importance. It controls the degree of parasitic reaction that results in the growth of the solid electrolyte interface (SEI) which governs the battery performances in terms of capacity retention, lifetime, etc... Herein, we show how cyclic voltammetry (CV) can be used to rapidly spot hints of electrolyte decomposition and determine whether the resulting species are either solubilized or adsorbed leading to the SEI formation. Using this approach, we identified a new electrolyte, which consists of a solution of $1 \mathrm{M} \mathrm{NaPF}_{6}$ in EC-DMC $(1: 1 \mathrm{v} / \mathrm{v}$ ratio) to which we added three additives namely vinylene carbonate (VC), sodium (oxalate) difluoro borate (NaODFB) and tris (trimethylsilyl) phosphite TMSPi. This novel electrolyte when implemented in today's practical full $\mathrm{Na}_{3} \mathrm{~V}_{2}\left(\mathrm{PO}_{4}\right)_{2} \mathrm{~F}_{3} / \mathrm{C}$ Na-ion cells gives the best high temperature performances in terms of cyclability and self-discharge. Using $\mathrm{CV}$ we could rationalize this finding and unambiguously prove that NaODFB is ruling the SEI formation while TMSPi is essential to control its growth and for capturing both $\mathrm{O}_{2}$ and acid impurities responsible for deleterious reactions occurring at relatively high potentials.

(C) The Author(s) 2019. Published by ECS. This is an open access article distributed under the terms of the Creative Commons Attribution 4.0 License (CC BY, http://creativecommons.org/licenses/by/4.0/), which permits unrestricted reuse of the work in any medium, provided the original work is properly cited. [DOI: 10.1149/2.0721915jes]

(cc) BY
\end{abstract}

Manuscript submitted September 3, 2019; revised manuscript received October 22, 2019. Published November 11, 2019.

Rechargeable Lithium-ion batteries are nowadays crucial for the development of portable electronic market and distinguished progresses have been made in terms of stability and safety during last decades. ${ }^{1}$ However, the continuous depletion of the Li reserves requires a concrete scientific effort aimed at the discovery of new sustainable energy storage devices, based on the more abundant $\mathrm{Na}$ alkali. ${ }^{2}$ Due to the low cost of this element, Na-ion batteries could potentially become an attractive solution for the large-scale storage of the highly intermittent solar and wind energy. Towards this purpose, researches have been focused to identify suitable electrode and electrolyte materials for Na-ion battery application. Few systems based on sodium layered oxide/Hard carbon (C) and $\mathrm{Na}_{3} \mathrm{~V}_{2}\left(\mathrm{PO}_{4}\right)_{2} \mathrm{~F}_{3}$ (NVPF)/C have already been demonstrated. ${ }^{3}$ Among them the NVPF / hard carbon (C) system which is the topic of this paper is the most promising because of both the structural stability and high redox potential of NVPF $(\sim 4 \mathrm{~V})$, however some electrolyte fine tuning remains to be done. A stable SEI (solid electrolyte interface) is fundamental to minimize side reactions between electrode and electrolyte, hence to enhance the battery performances. ${ }^{4-6}$ Thus it is of paramount importance to master its formation which changes with the involved chemistry. For instance, the milder acidity of $\mathrm{Na}^{+}$as compared to $\mathrm{Li}^{+}$modifies the nature of the SEI formation together with its increased solubility. Hence, the SEI with Na-ion batteries is relatively less stable than their Licounterparts ${ }^{7,8}$ and the SEI stability difference is more prominent at high temperatures.

From our recent studies, ${ }^{9}$ we observed a more pronounced dissolution of SEI component in presence of linear carbonate solvents such as DMC. More specifically, we demonstrated that the reductive decomposition products shuttle to and poison the positive electrode hence severely deteriorating the electrochemical performance at high temperatures. To reduce this deterioration we have designed a new electrolyte using solely cyclic carbonate solvents (EC-PC) together with vinylene carbonate (VC), sodium (oxalate) difluoro borate (NaODFB), propane sultone (PS) and succinonitrile (SN) as additives. ${ }^{10} \mathrm{NVPF} / \mathrm{C}$ $\mathrm{Na}$-ion cells having high temperature performances could then be realized but to the expense of practical issues associated to the high viscosity of this DMC-free electrolyte. Bearing in mind that the usage of linear carbonate is quite essential to minimize the electrolyte viscosity and improve its wettability to polyolefinic separator, ${ }^{11}$ we have tried to replace EC-PC by EC-DMC while maintaining the same additives,

${ }^{\mathrm{z}}$ E-mail: jean-marie.tarascon@ college-de-france.fr but the cell performance was deteriorated. So, we extended our search for new additives that could harmoniously work with DMC as well; that is to protect the NVPF electrode from the decomposition products of DMC. Interestingly, tris (trimethylsilyl) phosphite (TMSPi) was demonstrated to protect positive electrode in Li-ion batteries, ${ }^{12,13}$ hence our decision to explore its use in DMC-based sodium electrolyte to protect NVPF surface. We herein report a new $1 \mathrm{M}-\mathrm{NaPF}_{6} \mathrm{EC}-\mathrm{DMC}$ electrolyte solution containing three additives namely TMSPi, vinylene carbonate and NaODFB (Chart 1) that shows excellent cycling and self-discharge performances at $55^{\circ} \mathrm{C}$. The $\mathrm{VC}$ and $\mathrm{NaODFB}$ were maintained in our new electrolyte formulation because of their feasibility to give at the negative electrode a stable polymer matrix and a thin deposit of $\mathrm{NaF}$ nanocrystals as experienced in our early work

As of today, identifying a perfect electrolyte formulation with different additives working in synergy is quite complex as we mainly depend on the trial and error approach to choose the additives. Computational approaches have so far no success in predicting the synergy between various additives. ${ }^{14}$ In addition, the nature and the components of SEI formed are usually studied by both in situ and ex situ analytical techniques (XPS, TOFSIM, etc...) at large instrument facilities. Access to large instrument facilities to determine the outcome of electrochemical decomposition products (adsorbed vs solution) forming the SEI is time consuming rendering the search for new additives a slow process. Herein, we demonstrate how cyclic voltammetry (CV),

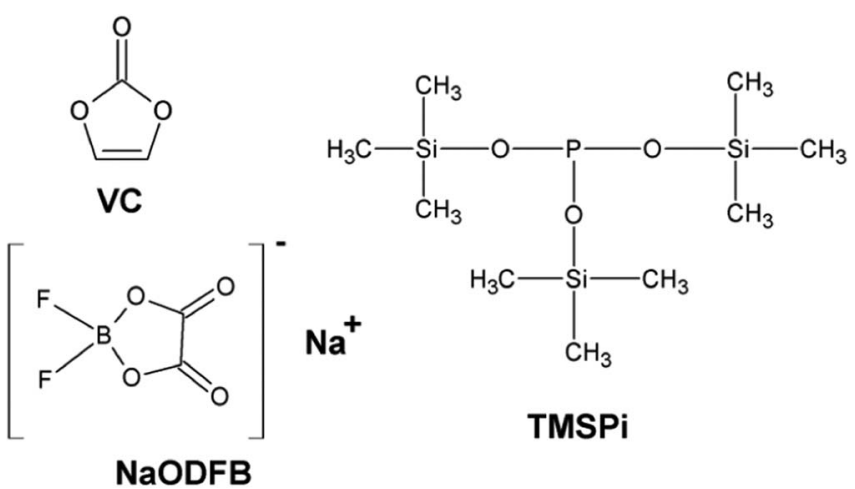


a well-known technique to the battery community, can be used differently as an elegant tool to rapidly provide qualitative and quantitative insights about the thermodynamics and kinetics of the reaction processes associated to each additive, hence enhancing the confection of new electrolytes. Within the field of batteries, CV has been used as an electrochemical tool for studying liquid electrolytes ${ }^{15-17}$ with the analysis being mainly restricted to very low scan rates $(v$ in the order of $1 \mathrm{mV} / \mathrm{s}$ ) and limited attention to the reverse oxidative scan at high potentials. Herein we show how adjusting the CV scan rate is essential to determine whether the species resulting from the reductive bond cleavage of additives are either adsorbed (e.g. forming the SEI) or remain in solution. Moreover, we even present an experimental protocol to access the degree of stability of the SEI formed with temperature. Overall, the CV technique explored here could be used as a screening test for the electrolyte additives and to identify the optimum combinations. A logical way to present our study could consist in showing the CV studies for all the additives we have tried prior reaching the optimum electrolyte formulation. For fear of being too long and loose the essence of the work, we rather decided to first present the battery performances and then show how this practical result can be rapidly confirmed and scientifically rationalized by $\mathrm{CV}$.

\section{Experimental}

Electrolyte preparation.-Our electrolytes were prepared by dissolving one molar $\mathrm{NaPF}_{6}$ (Stella, Japan) in a mixture of solvents composed of DMC (Sigma Aldrich, >99\%, anhydrous, or BASF, USA) and EC (Mitsubishi chemical, Japan), or a pure solvent such as PC (BASF, USA), acetonitrile (99.9\%, anhydrous, Acros) or diglyme (99.5\%, anhydrous, Sigma Aldrich) in the Arfilled glove box (MBraun MB200B). Lastly, prior to their use, all solvents were dried by adding molecular sieve (4 A, Sigma) till their water contents become lower than $10 \mathrm{ppm}$ as determined by Karl-Fisher titration (Metrohm 899 coulometer). Vinylene carbonate (VC, Sigma), tris(trimethylsilyl) phosphite (TMSPi, TCI) and home-made Sodium (oxalate) difluoro borate (NaODFB, the synthesis has been already reported ${ }^{10}$ ) were used as additives without further purification.

Electrochemical measurements of NVPF/C cells.$\mathrm{Na}_{3} \mathrm{~V}_{2}\left(\mathrm{PO}_{4}\right)_{2} \mathrm{~F}_{3}$ (NVPF, $\left.12.0 \mathrm{mg} / \mathrm{cm}^{2}\right)$ tapes were casted by spreading the slurries (NVPF materials, polyvinylidene difluoride and carbon black (the weight ratio is 90:4:6) within $\mathrm{N}$-methyl-2-pyrrolidone) onto $\mathrm{Al}$ foil. The hard carbon $\left(\mathrm{C}, 6.0 \mathrm{mg} / \mathrm{cm}^{2}\right)$ tapes were casted by spreading the slurries (hard carbon materials, carboxymethyl cellulose and carbon black (the weight ratio is $95: 2: 3$ ) within deionized water) onto $\mathrm{Al}$ foil. All of the electrodes were dried in a Buchi oven under vacuum (lower than $100 \mathrm{mbar}$ ) at 80 degree Celsius for $24 \mathrm{~h}$ prior to be transferred into glove box. The electrochemical performances of NVPF/C full cells were evaluated in 2032-type coin cells separated by one layer of glass fiber containing $150 \mu \mathrm{L}$ of desired electrolytes. All cells were galvanostatically cycled by using VMP3 or MPG2 potentiostat (Bio-Logic, France) at $55^{\circ} \mathrm{C}$ or $25^{\circ} \mathrm{C}$, and the cycling rates were calculated on the basis of NVPF material $(1 \mathrm{C}=128 \mathrm{~mA}$ $\left.\mathrm{g}^{-1}\right)$.

Cyclic voltammetry measurements. - The working electrode was a $3 \mathrm{~mm}$ diameter glassy carbon (Bio-Logic, France) disk carefully polished by using a suspension of alumina $(0.04 \mu)$, ultrasonically rinsed in water, rinsed by ethanol and dried before use. The counter electrode was a platinum wire, and a non-aqueous $\mathrm{Ag}^{+} / \mathrm{Ag}$ reference electrode (silver wire immersed in an acetonitrile/0.1 M tetrabutylammonium perchlorate/0.01 $\mathrm{M} \mathrm{AgNO}_{3}$ solution) was used for all the $\mathrm{CV}$ experiments. The potential values were then referred to the $\mathrm{Na}^{+} / \mathrm{Na}$ couple $\left(\mathrm{E}_{\mathrm{Na}+\mathrm{Na}}=-2.77 \mathrm{~V}\right.$ vs $\mathrm{Ag}^{+} / \mathrm{Ag}$, measured in the studied electrolyte $)$ or to the $\mathrm{Li}^{+} / \mathrm{Li}$ couple $\left(\mathrm{E}_{\mathrm{Li}+/ \mathrm{Li}}=-3.18 \mathrm{~V}\right.$ vs $\left.\mathrm{Ag}^{+} / \mathrm{Ag}\right)$. $\mathrm{CV}$ data were obtained by using a VMP3 potentiostat (Bio-Logic, France) and all the experiments were carried out in the Ar-filled glove box (MBraun MB200B).
Mass spectrometry analysis of the gas products.-The gases generated during the formation cycle of a 18650-type cell at $55^{\circ} \mathrm{C}$ have been recovered in an hermetic coffee bag enclosure and analyzed by using a trace GC ultra gas chromatograph (Thermo Scientific). ${ }^{18}$ The gas samples were transferred into the split/splitless injector maintained at $200^{\circ} \mathrm{C}$. The chromatographic separation was performed on a "HPPLOT/Q" polystyrene-divinylbenzene-based capillary column $(30 \mathrm{~m}$, $0.32 \mathrm{~mm}$ i.d., $20 \mathrm{~mm}$ ) from Agilent J \& W Technologies followed by a process using a post-capillary column "Rtx-1" (15 m, $0.25 \mathrm{~mm}$ i.d., $0.25 \mathrm{~mm}, 100 \%$ dimethyl polysiloxane) from Restek. The GC was interfaced with an ISQ mass spectrometer (Thermo Scientific). The compound identification was carried out by using the National Institutes of Standards (NIST) library.

\section{Results and Discussion}

Battery tests.-Cycling and self-discharge tests of NVPF/C full cells were performed at $55^{\circ} \mathrm{C}$ to find a suitable electrolyte for Na-ion batteries. All the experiments were carried out with an experimental protocol that consists in cycling the cell 10 times prior to performing one week self-discharge at $100 \%$ state of charge $(\sim 4.3 \mathrm{~V})$ and cycling again at $\mathrm{C} / 10$ rate $\left(1 \mathrm{C}=128 \mathrm{~mA} \mathrm{~g}^{-1}\right)$. $1 \mathrm{M}$ solution of $\mathrm{NaPF}_{6}$ in $\mathrm{EC}$ DMC (1:1 by volume) solution was taken as a mother electrolyte. The influence of additives on the electrochemical performance was studied separately on each single additive (VC, NaODFB and TMSPi) and then on the mixture of all three additives $(3 \% \mathrm{VC},+0.5 \% \mathrm{NaODFB},+1 \%$ TMSPi). The electrochemical performances were compared by taking into account the capacity retention of the cells (Figure 1a), capacity retention before and after one week of self-discharge as $\mathrm{Q}_{11 \text { th-dis }} / \mathrm{Q}_{11 \text { th-cha }}$ (discharge capacity divided by the charge capacity of the 11 th cycle) the percentage of recovered capacity as $\mathrm{Q}_{12 \text { th-dis }} / \mathrm{Q}_{11 \text { th-cha }}$ (Figure $1 \mathrm{~b}$ ) and the change in ohmic drop upon cycling (Figures 1c and 1d).

The cumulative performance analyses show that the best electrochemical performance was obtained with the mixture of three additives $(3 \% \mathrm{VC},+0.5 \% \mathrm{NaODFB},+1 \% \mathrm{TMSP})$. The single additives namely TMSPi and $\mathrm{VC}$ also show better performance with respect to capacity retention and self-discharge recovery capacity in comparison to the mother electrolyte. In contrast, addition of $0.5 \% \mathrm{NaODFB}$ deteriorates the capacity retention as compared to the mother electrolyte $1 \mathrm{M} \mathrm{NaPF}_{6}$ in EC-DMC since only $90 \%$ of the capacity was recovered after self-discharge tests. Interestingly the capacity decay is larger for TMSPi while the recovery is the greatest one (Figure 1b). This effect could be due to the easiness of the TMSPi oxidation that favors the reduction of NVPF. This contrasts with the use of NaODFB which acts mainly on reduction as will be confirmed later on.

To reveal the underlying reason of such performance variations of the NVPF/C cells with various electrolytes, the apparent resistance values of NVPF/C cells were retrieved from the voltage-current curves ${ }^{19}$ and shown in Figures 1c and 1d. A considerable increase in the ohmic drop was observed for the simple EC/DMC electrolyte over the cycle number at $55^{\circ} \mathrm{C}$, and an even larger growth was found with the addition of NaODFB that accounts for the drastic capacity decay as observed in Figure 1a. The use of VC or TMSPi sensibly reduces the ohmic drop raise and the best results were achieved by adding all the components (VC, NaODFB and TMSPi). Overall, compared to the single additives, the mixture of additives shows better electrochemical performance (Figure 1e), hence showing a synergy between different additives in the SEI creation. To understand this synergetic effect further, cyclic voltammetry experiments were used and are explained next.

Cyclic voltammetry.-Classical glassy carbon, as previously used in the battery field, ${ }^{20-22}$ was here selected as carbonaceous working electrode in order to model the hard carbon anode used in $\mathrm{Na}$-ion batteries. The choice for such an electrode is rooted in its planarity that leads to a significant simplification in terms of experimental procedure and reproducibility, but also in the well mastered theoretical treatment of the current-voltage plot for planar electrodes. ${ }^{23}$ By using relatively high scan rates, intercalation phenomena naturally occurring 

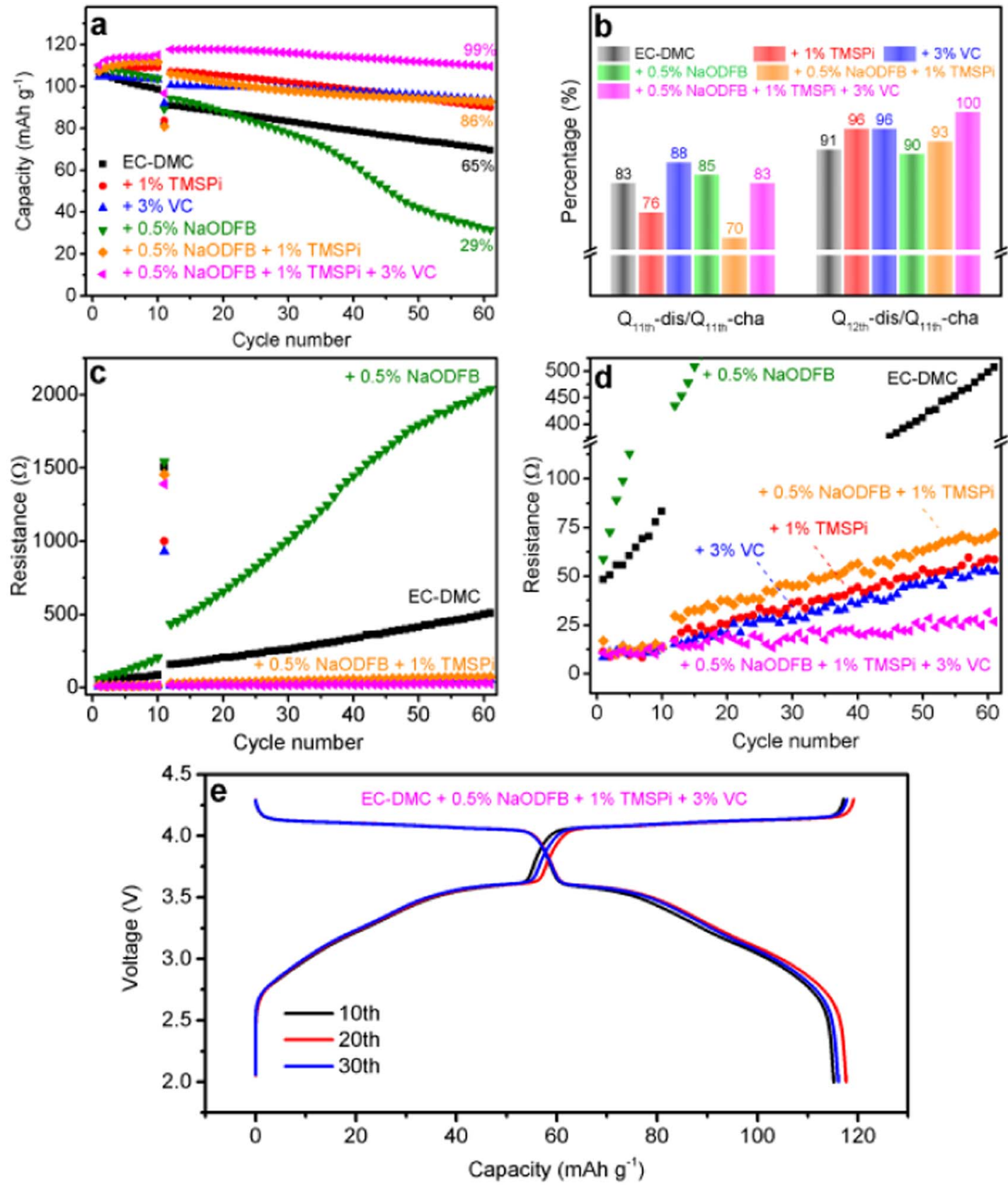

Figure 1. a, the cycling performances of NVPF/C cells with various electrolytes at $55^{\circ} \mathrm{C}$. b, the percentage of capacity retention and recovery after the self-discharge measurements of NVPF/C cells at $100 \%$ SoC for 1 week. c, the direct current resistance of NVPF/C cells during the $55^{\circ} \mathrm{C}$ cycling process. A zoom is reported in d. e, the voltage-capacity curve at $10^{\text {th }}, 20^{\text {th }}$ and $30^{\text {th }}$ cycle for the mixture of all three additives $(3 \% \mathrm{VC},+0.5 \% \mathrm{NaODFB},+1 \% \mathrm{TMSPi})$.

in the glassy carbon electrode ${ }^{24}$ are minimized in order to focus exclusively on the observation of the products (and possibly the reaction intermediates) of electrolyte reduction. Although cyclic voltammetry can assess the short time scale reactivity, the application of this technique in long-term analysis (e.g. the cycling stability of a battery) is not straightforward. However, a preliminary screening of new electrolytes could be performed by evaluating the stability over time of the passivating layer obtained via electrolyte reduction.

Firstly the electrochemical behavior of the mother electrolyte $(1 \mathrm{M}$ $\mathrm{NaPF}_{6}$ in a mixture of EC/DMC 1:1 in volume) was probed by a threeelectrode $\mathrm{CV}$ setup at room temperature. Glassy carbon and a Pt wire were used as working and counter electrode, respectively. All the experiments were performed against a non-aqueous $\mathrm{Ag}^{+} / \mathrm{Ag}$ reference electrode (silver wire immersed in acetonitrile/0.1 M tetrabutylammonium perchlorate/0.01 $\mathrm{M} \mathrm{AgNO}_{3}$ solution) and the potential val- ues were then referred to the $\mathrm{Na}^{+} / \mathrm{Na}$ couple $\left(\mathrm{E}_{\mathrm{Na}^{+} / \mathrm{Na}}=-2.77 \mathrm{~V}\right.$ vs $\mathrm{Ag}^{+} / \mathrm{Ag}$, measured in the studied electrolyte).

The $\mathrm{CV}$ of the solvent mixture shows some tiny reductive waves in the $2.2 \mathrm{~V}-1.6 \mathrm{~V}$ region (Figure $2 \mathrm{a}$ inset, green rectangle) while the main peak is located at ca. $1 \mathrm{~V} \mathrm{vs} \mathrm{Na}+/ \mathrm{Na}$ and becomes more evident by decreasing the scan rate from $100 \mathrm{mV} / \mathrm{s}$ to $20 \mathrm{mV} / \mathrm{s}$ (Figure $\mathrm{S} 1$ (a) and Figure 2a inset-red rectangle). When the potential is reversed, several unresolved oxidative waves appear at high potentials $(2.8 \mathrm{~V}-4.5 \mathrm{~V}$ vs $\mathrm{Na}^{+} / \mathrm{Na}$, marked by asterisks). They are related to the oxidation of species produced by the electrolyte reductive decomposition, as confirmed by the absence of intense peaks in the simple oxidation scan of the solvent (red trace in Figure 2a). By increasing the scan rate up to $2 \mathrm{~V} / \mathrm{s}$, two different waves could be revealed at ca. $3.2 \mathrm{~V} \mathrm{vs} \mathrm{Na}^{+} / \mathrm{Na}$ and $4.4 \mathrm{~V}$ vs $\mathrm{Na}^{+} / \mathrm{Na}$ (Figure $2 \mathrm{~b}$, black asterisks and Figure $\mathrm{S} 1(\mathrm{~b})$ ). The former could be attributed to the oxidation of an alkoxide species 

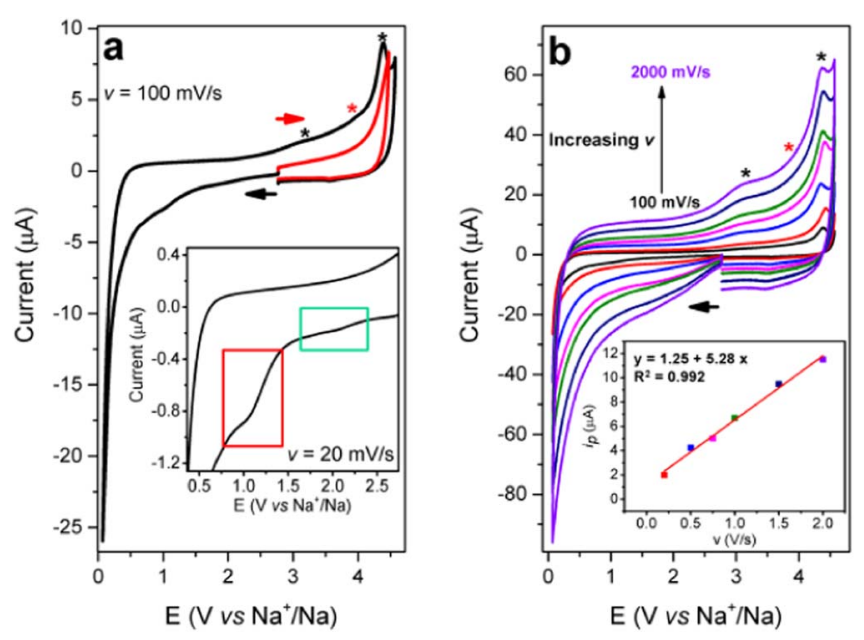

Figure 2. $\mathrm{CVs}$ of an $\mathrm{EC} / \mathrm{DMC}\left(1: 1\right.$ in volume, $\left.+1 \mathrm{M} \mathrm{NaPF}_{6}\right)$ solution at $25^{\circ} \mathrm{C}$. a, CVs at $100 \mathrm{mV} / \mathrm{s}$ toward low potentials (black) and high potential values (red). Both CVs correspond to the first scan after electrode polishing. The inset shows a zoom of the reduction waves at $20 \mathrm{mV} / \mathrm{s} . \mathrm{b}, \mathrm{CVs}$ at $100 \mathrm{mV} / \mathrm{s}$ (black), $200 \mathrm{mV} / \mathrm{s}$ (red), $500 \mathrm{mV} / \mathrm{s}$ (blue), $750 \mathrm{mV} / \mathrm{s}$ (magenta), $1000 \mathrm{mV} / \mathrm{s}$ (green), $1500 \mathrm{mV} / \mathrm{s}$ (navy) and $2000 \mathrm{mV} / \mathrm{s}$ (violet). The inset shows the $i_{p}$ vs $v$ plot for the oxidation peak at $3.2 \mathrm{~V} \mathrm{vs} \mathrm{Na}^{+} / \mathrm{Na}$. A glassy carbon ( $3 \mathrm{~mm}$ diameter) was used as working electrode.

by comparison with a CV experiment of sodium methoxide in the same solvent (Figure S2), in agreement with a previous report. ${ }^{9}$ However, it should be noted here that the formation of hydroxide $\left(\mathrm{OH}^{-}\right)$instead of sodium methoxide should also be taken into account since this species could be simply produced by reduction of $\mathrm{O}_{2}$ traces in the presence of water ${ }^{25-27}$ within the $2.3 \mathrm{~V}-1.5 \mathrm{~V}$ potential window ${ }^{28}$ or by $\mathrm{H}_{2} \mathrm{O}$ reduction at lower potentials. ${ }^{29,30}$ The peak corresponding to the $\mathrm{OH}^{-}$oxidation was reported to be at $+0.75 \mathrm{~V}$ vs SCE in DMSO, ${ }^{27}$ corresponding to $+0.45 \mathrm{~V}$ vs $\mathrm{Ag}^{+} / \mathrm{Ag}\left(+3.22 \mathrm{~V}\right.$ vs $\left.\mathrm{Na}^{+} / \mathrm{Na}\right)$. A similar peak was observed after polarizing the electrode at $-2.7 \mathrm{~V}$ vs $\mathrm{Ag}^{+} / \mathrm{Ag}$ in a $\mathrm{CH}_{3} \mathrm{CN}$ solution of $\mathrm{NaPF}_{6}(1 \mathrm{M})$, hence providing further support for the possible formation of hydroxides (Figure S3). The oxidation peak observed after addition of sodium methoxide in the DMC based electrolytes could then be simply related to $\mathrm{OH}^{-}$produced by the hydrolysis of alkoxide. Hence, to avoid any discrepancies, we label this product as simply 'oxide' throughout the manuscript. The elongated shape of the wave at $4.4 \mathrm{~V} \mathrm{vs} \mathrm{Na}{ }^{+} / \mathrm{Na}$ suggests the existence of another weak and unresolved peak at ca. $3.9 \mathrm{~V}$ vs $\mathrm{Na}^{+} / \mathrm{Na}$ (red asterisk in Figure $2 \mathrm{a}$ and Figure $2 \mathrm{~b}$ ). If the peak intensity $\left(i_{p}\right)$ of the wave at $3.2 \mathrm{~V}$ vs $\mathrm{Na}^{+} / \mathrm{Na}$ is plotted as a function of the scan rate (v) a linear correlation is achieved, meaning that the oxide species is adsorbed (or simply precipitated) on the electrode surface (at least in a short term period) and effectively contributes to the anode SEI formation (Figure $2 b$ inset and Figure S4). ${ }^{23}$ Conversely, the peak at ca. $4.4 \mathrm{~V}$ vs $\mathrm{Na}^{+} / \mathrm{Na}$ corresponds to the oxidation of an unknown species that is likely diffusive as observed by the linear relationship between the current and the square root of scan rate (Figure S5).

To investigate the potential required for the formation of the redoxactive species produced by the electrolyte reduction, two different approaches were followed. In the first one, the electrode potential is cycled five times at $100 \mathrm{mV} / \mathrm{s}$ from $2.17 \mathrm{~V} \mathrm{vs} \mathrm{Na}^{+} / \mathrm{Na}$ to a particular value $\mathrm{E}\left(\mathrm{E}<2.17 \mathrm{~V}\right.$ vs $\left.\mathrm{Na}^{+} / \mathrm{Na}\right)$ in order to accumulate the degradation products. Then, an oxidative scan is performed to reveal by oxidation any new species produced in the reduction process. Starting from $\mathrm{E}=$ $1.37 \mathrm{~V}$ vs $\mathrm{Na}^{+} / \mathrm{Na}$, an oxide is the first redox-active product to be observed (black asterisk in Figure S6), while for $\mathrm{E}=0.57 \mathrm{~V} \mathrm{vs} \mathrm{Na}^{+} / \mathrm{Na}$ the peak at $3.90 \mathrm{~V}$ starts to grow and becomes the most intense one (red asterisk). According to a previous work, this wave could be reasonably attributed to the oxidation of an alkyl carbonate species deposed on the electrode surface (as shown by the linearity in the $i_{p}$ vs $v$ plot of Figure 3). ${ }^{9}$
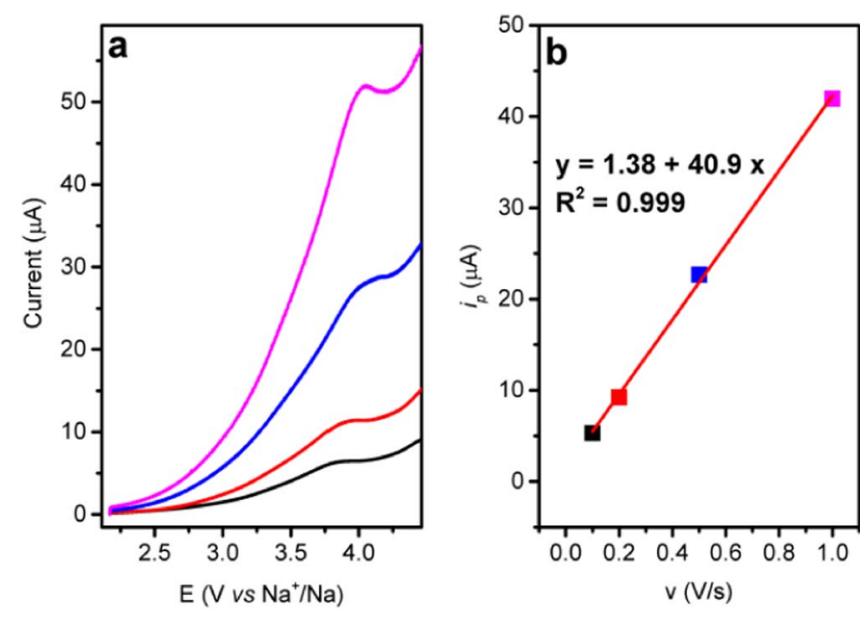

Figure 3. a, linear scans at $100 \mathrm{mV} / \mathrm{s}$ (black), $200 \mathrm{mV} / \mathrm{s}$ (red), $500 \mathrm{mV} / \mathrm{s}$ (blue) and $1000 \mathrm{mV} / \mathrm{s}$ (magenta) of the SEI produced by five scans at $100 \mathrm{mV} / \mathrm{s}$ between $2.17 \mathrm{~V}$ vs $\mathrm{Na}^{+} / \mathrm{Na}$ and $0.07 \mathrm{~V}$ vs Na$/ / \mathrm{Na} . \mathrm{b}, i_{p}$ vs $v$ plot for the oxidation peak at $3.9 \mathrm{~V}$ vs $\mathrm{Na}^{+} / \mathrm{Na}$ confirming the adsorption of the related species on the electrode surface. $\mathrm{T}=25^{\circ} \mathrm{C}$.

In the second method, the potential is varied at $1 \mathrm{~V} / \mathrm{s}$ to a particular vertex value $\mathrm{E}$ and then this potential is held for one minute before recording the reverse oxidative scan at the same speed. The oxide reoxidation peak was observed starting from $\mathrm{E}=1.97 \mathrm{~V}$ vs $\mathrm{Na}^{+} / \mathrm{Na}$ (asterisk in Figure S7a). Overall, the cyclic voltammetry experiments with $1 \mathrm{M} \mathrm{NaPF}_{6}$ in EC-DMC showed no specific peak corresponding to the reduction of $\mathrm{EC}$ at the negative electrode. The tiny reductive waves in the $2.2 \mathrm{~V}-1.6 \mathrm{~V}$ (green rectangle in Figure 2a inset) region may be associated with the $\mathrm{O}_{2}$ traces and acid impurities present in the electrolyte. ${ }^{30}$ The peak at ca. $1 \mathrm{~V}$ vs Na${ }^{+} / \mathrm{Na}$ (red rectangle in Figure 2a inset) could be attributed to the reduction of $\mathrm{H}_{2} \mathrm{O}$ traces or other impurities while only the huge reduction wave at very low potential $\left(\sim 0 \mathrm{~V}\right.$ vs $\left.\mathrm{Na}^{+} / \mathrm{Na}\right)$ may be related to the decomposition of the solvent.

Next, we studied the role of each additive by adding one by one consecutively and following the $\mathrm{CV}$ as explained before. After the addition of vinylene carbonate $(3 \% \mathrm{w} / \mathrm{w}$ ), the $\mathrm{CV}$ at $100 \mathrm{mV} / \mathrm{s}$ (Figure S8a) did not reveal a significant change but an extra-peak was observed at ca. $0.5 \mathrm{~V} \mathrm{vs} \mathrm{Na}+/ \mathrm{Na}$ for $v=20 \mathrm{mV} / \mathrm{s}$ (Figure S8b). The same three redox-active products of electrochemical electrolyte decomposition were identified, although in a different ratio with respect to the VC-free case (asterisks in Figure S9). The oxide species starts to be detected at $\mathrm{E}<1.57 \mathrm{~V}$ vs $\mathrm{Na}^{+} / \mathrm{Na}$ according to the first method (Figure S9) and at $\mathrm{E}<1.87 \mathrm{~V}$ vs Na${ }^{+} / \mathrm{Na}$ following the second approach (Figure $\mathrm{S} 7 \mathrm{~b}$ ). The deposition of this species on the electrode surface was proved by the perfect linearity in the $i_{p}$ vs $v$ plot (Figure S10). When NaODFB $(0.5 \% \mathrm{w} / \mathrm{w})$ was dissolved in the medium, an intense and purely diffusive (Figures S11, S12 and S13) reduction peak appeared at $0.97 \mathrm{~V}$ vs $\mathrm{Na}^{+} / \mathrm{Na}$. The pre-peak at $1.08 \mathrm{~V}$ vs $\mathrm{Na}^{+} / \mathrm{Na}$ is probably related to the aging of the solution during the long-time experiment in glove box, as confirmed by the absence of this trace in a freshly prepared solution (Figure S14) and in a propylene carbonate solution of NaODFB (Figure S15). A drastic change was observed in the reverse scan at high potential values, implying that the SEI formation now highly depends on the presence of NaODFB (Figure S11). These re-oxidation waves have to be attributed to the oxidative SEI decomposition since they are missing in the simple oxidation scan recorded for the ECDMC mixture (Figure S14, red trace). The formation of oxide species adsorbed (as shown in Figure S16) on the electrode was detected at $1.67 \mathrm{~V}$ vs $\mathrm{Na}^{+} / \mathrm{Na}$ and $1.87 \mathrm{~V}$ vs $\mathrm{Na}^{+} / \mathrm{Na}$ according to the first and second method, respectively (Figures S17 and S7c). With the addition of $1 \%(\mathrm{w} / \mathrm{w}) \mathrm{TMSPi}$, an intense peak $\left(E_{p}=3.86 \mathrm{~V}\right.$ vs $\left.\mathrm{Na}^{+} / \mathrm{Na}\right)$ related to the oxidation of TMSPi was observed at high potentials (Figure 4), which is consistent with what reported in the literature. ${ }^{13}$ The peak 


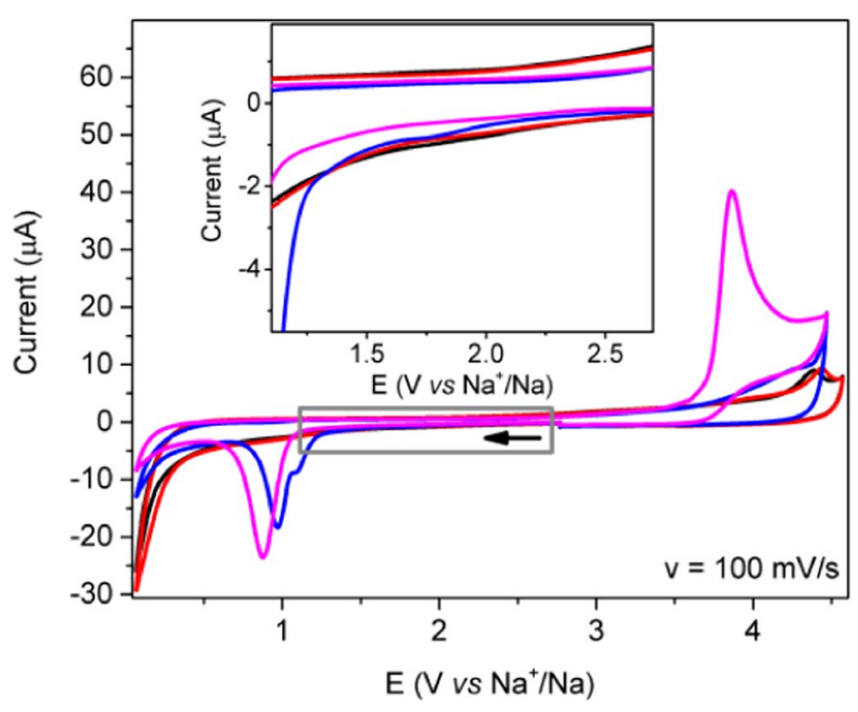

Figure 4. $\mathrm{CV}$ s of an $\mathrm{EC} / \mathrm{DMC}\left(1: 1\right.$ in volume, $\left.+1 \mathrm{M} \mathrm{NaPF}_{6}\right)$ solution containing no additives (black), $3 \% \mathrm{VC}$ (red), $3 \% \mathrm{VC}+0.5 \% \mathrm{NaODFB}$ (blue), and $3 \% \mathrm{VC}+0.5 \% \mathrm{NaODFB}+1 \%$ TMSPi (magenta). The inset shows a zoom of the small reduction waves observed before the NaODFB reduction peak. All CVs correspond to the first scan after electrode polishing. $v=100 \mathrm{mV} / \mathrm{s}$. $\mathrm{T}=25^{\circ} \mathrm{C}$.

related to the NaODFB reduction underwent a cathodic $90-\mathrm{mV}$ shift $\left(E_{p}=0.88 \mathrm{~V}\right.$ vs $\left.\mathrm{Na}^{+} / \mathrm{Na}\right)$ and increased in intensity (Figure 4). The pre-peak at $1.08 \mathrm{~V}$ vs $\mathrm{Na}^{+} / \mathrm{Na}$ disappeared, together with all the reduction processes occurring before the $\mathrm{NaODFB}$ reduction. A similar phenomenon was also observed in PC electrolyte (Figure S18). No oxide species was detected before the foot of the NaODFB reduction wave for $\mathrm{E}>1.27 \mathrm{~V}$ vs Na${ }^{+} / \mathrm{Na}$, as highlighted in Figures 5a and Figure S19 according to method 2 and method 1, respectively. A linear correlation between the peak current and the scan rate proved the deposition of this species on the electrode surface (Figure 5a, inset). To conclude, among the three additives we studied here, solely NaODFB reduces within the studied potential window and participates directly on the SEI layer creation. VC and TMSPi seem to be involved only
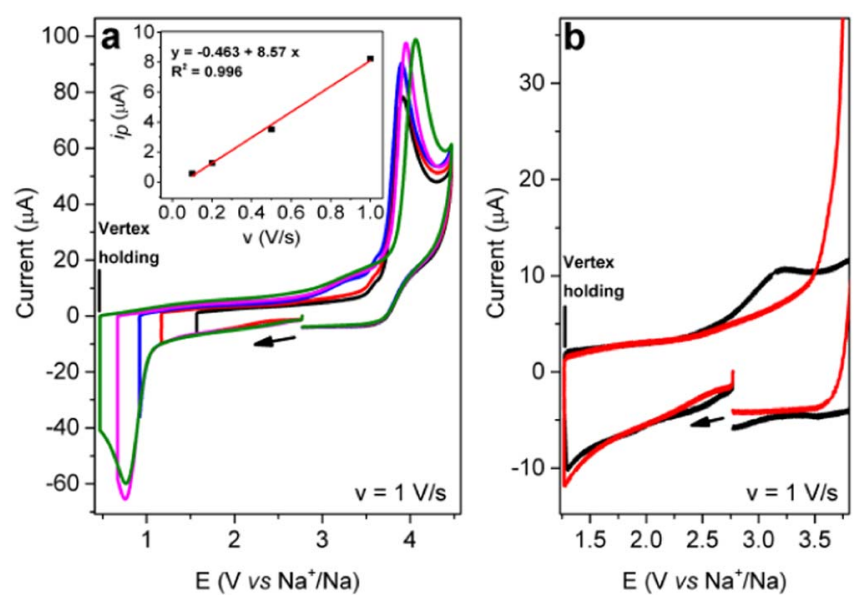

Figure 5. a, CVs on an EC/DMC (1:1 in volume, $+1 \mathrm{M} \mathrm{NaPF}_{6},+3 \% \mathrm{VC}$, $+0.5 \% \mathrm{NaODFB},+1 \% \mathrm{TMSPi})$ solution at $25^{\circ} \mathrm{C}(v=1 \mathrm{~V} / \mathrm{s}$, one-minute holding of the vertex potential E). $\mathrm{E}=1.57 \mathrm{~V}$ (black), $1.17 \mathrm{~V}$ (red), $0.92 \mathrm{~V}$ (blue), $0.67 \mathrm{~V}$ (magenta) and $0.47 \mathrm{~V} \mathrm{vs} \mathrm{Na} / / \mathrm{Na}$ (green). The inset shows the $i_{p}$ vs $v$ plot for the oxide oxidation peak. b, $\mathrm{CVs}$ at $25^{\circ} \mathrm{C}(v=1 \mathrm{~V} / \mathrm{s}$, one-minute holding of the vertex potential $\mathrm{E}=1.27 \mathrm{~V} \mathrm{vs} \mathrm{Na} / \mathrm{Na})$ of an $\mathrm{EC} / \mathrm{DMC}(1: 1 \mathrm{in}$ volume, $+1 \mathrm{M} \mathrm{NaPF}_{6},+3 \% \mathrm{VC},+0.5 \% \mathrm{NaODFB}$ ) solution without (black) and with (red) $1 \%$ TMSPi.
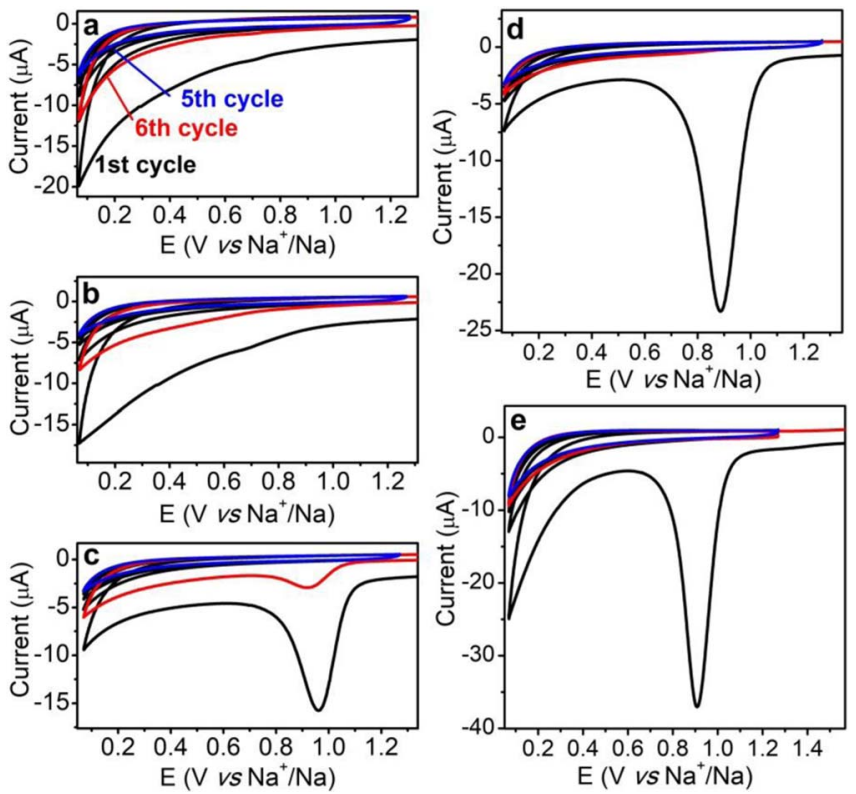

Figure 6. Five potential cycles to produce the SEI (black) and following CV after five minutes resting (red). $v=100 \mathrm{mV} / \mathrm{s}$. a, EC/DMC (1:1 in volume, $\left.+1 \mathrm{M} \mathrm{NaPF}_{6}\right)$ solution at $25^{\circ} \mathrm{C} . \mathrm{b}, \mathrm{EC} / \mathrm{DMC}\left(1: 1\right.$ in volume, $+1 \mathrm{M} \mathrm{NaPF}_{6}$, $+3 \% \mathrm{VC})$ solution at $25^{\circ} \mathrm{C}$. c, EC/DMC (1:1 in volume, $+1 \mathrm{M} \mathrm{NaPF}_{6},+$ $3 \% \mathrm{VC},+0.5 \% \mathrm{NaODFB})$ solution at $25^{\circ} \mathrm{C}$. d, EC/DMC (1:1 in volume, + $1 \mathrm{M} \mathrm{NaPF}_{6},+3 \% \mathrm{VC},+0.5 \% \mathrm{NaODFB},+1 \% \mathrm{TMSPi}$ ) solution at $25^{\circ} \mathrm{C}$. e, EC/DMC ( $1: 1$ in volume, $+1 \mathrm{M} \mathrm{NaPF}_{6},+3 \% \mathrm{VC},+0.5 \% \mathrm{NaODFB},+1 \%$ TMSPi) solution at $55^{\circ} \mathrm{C}$. The electrode was polished before the experiment for all the electrolyte compositions.

indirectly in the SEI layer formation. Notably, when hard carbon was used as working electrode instead of glassy carbon similar CVs were recorded, confirming the solidity of the approximation in the choice of the electrode material (Figure S20).

Importance of the additives.-To further probe the role of each additive on the stability of SEI, we carried out a set of new cyclic voltammetry experiments, by following the qualitative CV study reported by Aurbach et al. with a partial modification. ${ }^{31}$ For each electrolyte composition the SEI was produced by performing five potential cycles at $100 \mathrm{mV} / \mathrm{s}$ to reach a minimum potential of $0.07 \mathrm{~V} \mathrm{vs} \mathrm{Na} / \mathrm{Na}$ (Figure S21). Due to the passivation phenomena, the measured current decreased cycle by cycle to stabilize before the fifth one. Then the electrode was left at open-circuit potential for five minutes, before recording another CV (sixth cycle). If the formed SEI is stable without any dissolution during the 5 minutes rest period, there should be an overlap between the fifth and the sixth cycle without any new reduction peak. If there is a partial or complete dissolution of SEI during the rest period, the formed bare electrode surface will lead to new reduction processes on the sixth cycle. It is worthy to precise that an arbitrary rest period was chosen to compare the intrinsic passivation ability of the different mixtures. Due to the huge difference in terms of electrolyte volume/electrode surface ratio with the real coin cells conditions, it is not possible to obtain in this way the exact SEI stability corresponding to the cycling experiments but only a preliminary comparison among electrolytes. A low stability of the SEI was observed for an EC/DMC 1:1 (v/v) solution containing $1 \mathrm{M} \mathrm{NaPF}_{6}$ (Figure 6a) and with the addition of 3\% VC (Figure 6b), in agreement with previous data in the literature. ${ }^{32}$ Conversely, the high SEI stability recorded for an EC/DMC 1:1 (v/v) solution containing $1 \mathrm{M} \mathrm{LiPF}_{6}$ and 2\% VC (Figure S22) matches with the good cycling stability of Li-ion batteries containing $\mathrm{VC}$ as additive. ${ }^{17}$ Even after the addition of $0.5 \% \mathrm{NaODFB}$ to the electrolyte mixture $\left(1 \mathrm{M} \mathrm{NaPF}_{6}+3 \% \mathrm{VC}\right.$ in EC/DMC 1:1), a small reduction peak appears in the $6^{\text {th }}$ cycle showing the poor stability and partial dissolution of SEI (Figure $6 \mathrm{c}$ ). Finally, 
ideal condition with sixth CV cycle overlapping exactly with the $5^{\text {th }}$ one was reached only after the addition of TMSPi as a last additive, pointing out the synergy among the different components (Figure 6d).

The role of vinylene carbonate as additive for Li-ion batteries and the importance of this molecule in the formation of stable interfaces have been already discussed in previous reports. ${ }^{17,33}$ Moreover, the reactivity of the $\mathrm{C}=\mathrm{C}$ double bond toward polymerization reactions ${ }^{34,35}$ can be fundamental in the SEI creation even if the reduction of VC itself does not occur. Up to now, TMSPi is mainly known as a high-voltage additive since it can react directly with the traces of $\mathrm{HF}, \mathrm{H}_{2} \mathrm{O}$ and $\mathrm{PF}_{5}$ responsible for the metal dissolution at the cathode and produce a protective cathode film. ${ }^{12,36}$ Interestingly, his role in the stabilization of the anode SEI was studied in Li-ion batteries by Han et al. ${ }^{37} \mathrm{NaODFB}$ was proposed as new electrolyte salt for Na-ion batteries in 2015, showing promising results in terms of rate capability and reversible capacity in $\mathrm{Na} / \mathrm{Na}_{0.44} \mathrm{MnO}_{2}$ half cells. ${ }^{38}$

As observed from our $\mathrm{CV}$ experiments, $\mathrm{NaODFB}$ is an essential additive for the SEI formation and an intense peak at $0.97 \mathrm{~V} \mathrm{vs} \mathrm{Na} / \mathrm{Na}$ is associated to the reduction of this species. The sharp-shape of this purely diffusive reduction wave demonstrates a partial self-inhibition of the glassy carbon surface during the electrochemical process. ${ }^{39}$ However, the NaODFB reduction peak is partially observed in $\mathrm{CV}$ after five minutes (Figure 6c), suggesting that the SEI obtained at this stage is not completely stable. The huge improvement in stability registered after TMSPi addition can be rationalized by an in-depth analysis of the $\mathrm{CV}$ in Figure 4, inset. In the absence of this additive, other parasitic reactions occur at relatively high potentials $\left(\mathrm{E}>1.2 \mathrm{~V}\right.$ vs $\left.\mathrm{Na}^{+} / \mathrm{Na}\right)$ and are responsible for the formation of products including the redoxactive sodium oxide species. This compound is mainly adsorbed on the electrode surface but not completely passivating, as demonstrated by the observation of the NaODFB reduction peak at a lower potential (Figure 4). Conversely, in the presence of TMSPi no adsorbed oxide species is produced before the NaODFB reduction starts (Figure 5b).

In this regard, the positive effect (in terms of both thermodynamics and kinetics) of Lewis and Brønsted acids toward the reduction processes and reductive bond cleavages has been extensively discussed in the literature. ${ }^{40-42}$ Some acidic impurities may thus be responsible for the reduction processes detected at $\mathrm{E}>1.2 \mathrm{~V}$ vs $\mathrm{Na}^{+} / \mathrm{Na}$. According to our results, the role of TMSPi as $\mathrm{H}_{2} \mathrm{O}, \mathrm{PF}_{5}$ and HFscavenger to suppress side-reactions and control the SEI formation at the anode compartment appears fundamental. Moreover, some papers in the literature reported the $\mathrm{O}_{2}$-scavenging properties of $\mathrm{TMSPi}^{43,44}$ and this factor may be essential for controlling the first steps of the SEI formation at high potentials, by scavenging the $\mathrm{O}_{2}$ traces in the electrolyte responsible for the formation of adsorbed hydroxide. The significant increase of the NaODFB reduction peak upon TMSPi addition (Figure 4, Figure S14 and Figure S18) further points out the synergy between these two additives during the formation of the passivating layer. This effect may be simply due to the limited production of adsorbed oxide at higher potential, as aforementioned. In the absence of TMSPi a partial blocking of the electrode surface may occur, driving to a lowering of the NaODFB reduction peak current. By addition of TMSPi, this partial passivation effect is suppressed and the $\mathrm{NaODFB}$ reduction peak may increase consequently. However, another possible explanation of this phenomenon has to be considered. The passivation process triggered by the reduction of NaODFB is reasonably associated to the deposition of products (denoted as P) on the electrode surface. In order to describe this system, we can propose the following simple mechanism:

$$
\begin{gathered}
\mathrm{ODFB}^{-}+\mathrm{e}^{-} \rightleftarrows[\mathrm{ODFB}]^{2-} \\
{[\mathrm{ODFB}]^{2-} \rightarrow \mathrm{P}} \\
\mathrm{P} \rightarrow \text { Adsorbed species } \\
\text { TMSPi }+\mathrm{P} \rightarrow \text { Dissolved species }
\end{gathered}
$$

The reaction between TMSPi and P (Eq. 4) could compete with the formation of adsorbed species (Eq. 3) and slow down the electrode passivation, accounting for the increase of the NaODFB reduction peak. Keeping in mind that $\mathrm{ODFB}^{-}$is generally considered responsible for the production of $\mathrm{F}^{-}$(labeled P in Eq. 2) ${ }^{45}$ and that TMSPi is an efficient $\mathrm{F}^{-}$scavenger due to the formation of a strong Si-F bond (Eq. 4), ${ }^{36,46}$ the interaction between these two additives can produce fluorotrimethyl silane $\left(\left(\mathrm{CH}_{3}\right)_{3} \mathrm{SiF}\right)$. The evolution of this gas was indeed observed by mass spectrometry coupled to gas-chromatography during the formation cycle of our NVPF/C full cells at $55^{\circ} \mathrm{C}$ (Figure $\mathrm{S} 23)$. Hence the formation of $\left(\mathrm{CH}_{3}\right)_{3} \mathrm{SiF}$ could be essential to control the NaF-based SEI creation and avoid its excessive growth over cycling. Moreover a huge increase in the SEI resistance was registered over cycling with NaODFB as only additive while the addition of TMSPi significantly suppressed the impedance growth (Figures $1 \mathrm{c}$ and 1d). In order to further prove this assumption, the NaODFB reduction was studied by CV in the presence of $1 \%$ tris (trimethylsilyl) phosphate (Figure $\mathrm{S} 24 \mathrm{a}$ ), bearing the same $\left(\mathrm{CH}_{3}\right)_{3} \mathrm{Si}$ - group. Unlike the TMSPi case, the tiny reduction waves in the $2.2 \mathrm{~V}-1.6 \mathrm{~V}$ region were not suppressed but a huge increase of the NaODFB reduction peak occurred. A similar experiment was then performed with small amounts of sodium tetraethyl borate, additive known to react with water and acids (Figure S24b). ${ }^{47}$ The suppression of the parasitic processes herein detected did not result in a significant increase of the NaODFB reduction peak, meaning that the peak enhancing with TM$\mathrm{SPi}$ is mainly due to the $\mathrm{F}^{-}$scavenger properties of that additive. In summary, TMSPi can assist the SEI formation via NaODFB reduction by the formation of $\left(\mathrm{CH}_{3}\right)_{3} \mathrm{SiF}$ and this synergy results in the limited and controlled growth of the SEI.

Experiments at $55^{\circ} \mathrm{C}$.-The electrochemical behavior of the electrolyte was then studied at $55^{\circ} \mathrm{C}$. At this temperature, the oxide species are produced in correspondence of the NaODFB reduction as well (Figure S25). The adsorption on the glassy carbon was confirmed by the linearity in the $i_{p}$ vs $v$ plot (Figure S26). As evidenced in Figure $6 \mathrm{e}$, the passivating SEI formed by this electrolyte proved to be very stable over the time even at high temperature.

Electrochemical stability window of the SEI.-An analysis of the electrochemical stability window of the SEI was carried out using cyclic voltammetry again, however by studying the oxidation process and allowing the formed SEI to oxidize partially/ completely. The experiment could be used to determine the maximum potential at which the carbon electrode can be fixed without destroying the formed SEI. Firstly, the passivating interphase was formed by performing five $\mathrm{CV}$ cycles at $100 \mathrm{mV} / \mathrm{s}$ from $1.27 \mathrm{~V}$ vs $\mathrm{Na}^{+} / \mathrm{Na}$ to $0.07 \mathrm{~V}$ vs $\mathrm{Na}^{+} / \mathrm{Na}$. Then a $\mathrm{CV}$ was recorded going from $1.27 \mathrm{~V}$ vs $\mathrm{Na}^{+} / \mathrm{Na}$ to a particular potential $\mathrm{E}$ (with $\mathrm{E}>1.27 \mathrm{~V}$ vs $\mathrm{Na}^{+} / \mathrm{Na}$ ) before reversing the scan to reach $0.07 \mathrm{~V}$ vs $\mathrm{Na}^{+} / \mathrm{Na}$. The first segment of the $\mathrm{CV}$ should eventually oxidize the products of the electrolyte reduction while the second one should reveal if the passivating layer has been removed by oxidation (by the re-appearance of the NaODFB reduction peak). The experiment was carried out mainly for our best performing electrolyte $1 \mathrm{M} \mathrm{NaPF}_{6}$ in EC-DMC with $3 \% \mathrm{VC},+0.5 \% \mathrm{NaODFB},+1 \% \mathrm{TMSPi}$ (Figure 7). By slowly increasing the oxidation potential, the SEI layer was stable up to $3.57 \mathrm{~V}$ on oxidation. NaODFB reduction peak partially re-appears for $\mathrm{E}>3.57 \mathrm{~V}$ vs $\mathrm{Na}^{+} / \mathrm{Na}$ indicating the loss of the passivation character at this potential value (Figure 7). Analogously, the experiment at $55^{\circ} \mathrm{C}$ showed a partial decomposition of the SEI for $\mathrm{E}>3.87 \mathrm{~V}$ vs $\mathrm{Na}^{+} / \mathrm{Na}$ (Figure S27).

To summarize, simple CV experiments with slight modifications were used to follow the reduction process of different additives, synergy between different additives and also the solubility, electrochemical stability of the formed SEI layer. Equally, we extended our approach to other systems as already demonstrated with electrolytes for the Li-ion technology (Figure S22). As a proof of concept, we have also carried out similar experiments for diglyme-based electrolyte with same additives and are described in supplementary information (Figure S28). Good results in terms of capacity retention were obtained at $25^{\circ} \mathrm{C}$, with a significant improvement of the previously reported data for NVPF/C batteries in a glyme-based electrolyte. ${ }^{48}$ 

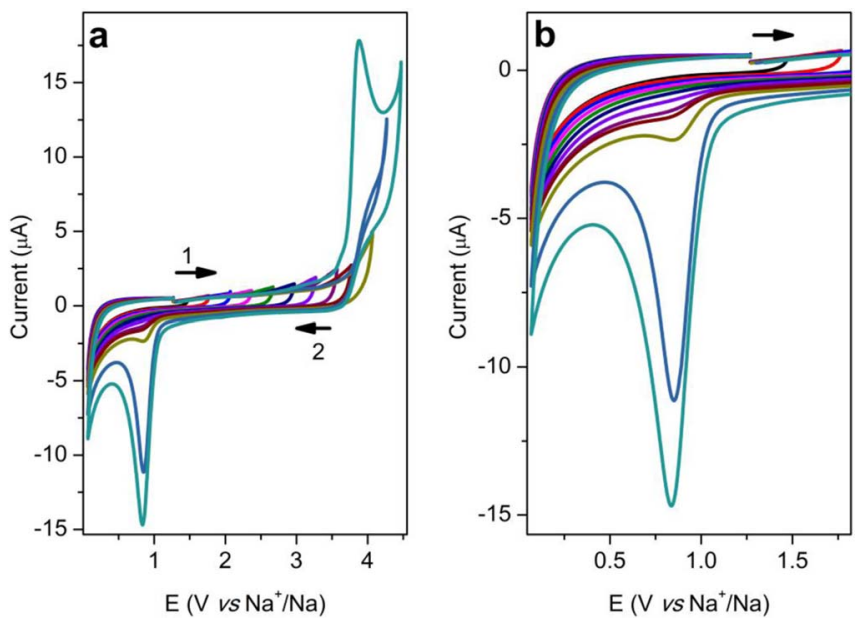

Figure 7. a, CVs at $100 \mathrm{mV} / \mathrm{s}$ of the SEI produced by five scans (not reported in the figure) between $1.27 \mathrm{~V} \mathrm{vs} \mathrm{Na}^{+} / \mathrm{Na}$ and $0.07 \mathrm{~V} \mathrm{vs} \mathrm{Na}+/ \mathrm{Na}$ for an EC/DMC $\left(1: 1\right.$ in volume, $\left.+1 \mathrm{M} \mathrm{NaPF}_{6},+3 \% \mathrm{VC},+0.5 \% \mathrm{NaODFB},+1 \% \mathrm{TMSPi}\right)$ solution at $25^{\circ} \mathrm{C}$. Positive vertex potential $=1.47 \mathrm{~V}$ (black), $1.77 \mathrm{~V}($ red $), 2.07 \mathrm{~V}$ (blue), $2.37 \mathrm{~V}$ (magenta), $2.67 \mathrm{~V}$ (green), $2.97 \mathrm{~V}$ (navy), $3.27 \mathrm{~V}$ (violet), $3.57 \mathrm{~V}$ (purple), $3.77 \mathrm{~V}$ (wine), $4.07 \mathrm{~V}$ (dark yellow), $4.27 \mathrm{~V}$ (gray) and $4.47 \mathrm{~V}$ vs $\mathrm{Na}^{+} / \mathrm{Na}$ (light blue). A zoom of the NaODFB reduction peak is reported in $\mathrm{b}$.

\section{Conclusions}

We herein reported a new electrolyte composition for $\mathrm{Na}$-ion batteries consisting in an EC/DMC (1:1 in volume, $+1 \mathrm{M} \mathrm{NaPF}_{6},+3 \% \mathrm{VC}$, $+0.5 \% \mathrm{NaODFB},+1 \% \mathrm{TMSPi}$ ) solution. This formulation shows remarkable specific capacity retention and self-discharge performances at $55^{\circ} \mathrm{C}$ during cycling tests in coin cells, by using NVPF and C as cathode and anode, respectively. A cyclic voltammetry analysis led to an in situ probing of the SEI formation in these carbonate based solvents. Redox-active products of the reductive electrolyte fragmentation, such as $\mathrm{RO}^{-}$(where $\mathrm{R}=-$ alkyl or $-\mathrm{H}$ ) and alkyl carbonate, were identified as well as the redox potential required for their formation. The adsorption of these compounds on the electrode surface was proved by varying the scan rate in the $\mathrm{CV}$ experiment. Moreover, the electrochemical behavior of an EC/DMC (1:1 in volume, $\left.+1 \mathrm{M} \mathrm{NaPF}_{6}\right)$ solution containing vinylene carbonate (VC), sodium (oxalate) difluoro borate (NaODFB) and tris (trimethylsilyl) phosphite (TMSPi) as additives was elucidated. According to this study, $\mathrm{NaODFB}$ is reduced at $0.88 \mathrm{~V} \mathrm{vs} \mathrm{Na}^{+} / \mathrm{Na}$ and controls the interphase creation while TMSPi minimizes the $\mathrm{O}_{2}$ reduction and other deleterious, parasitic and acidboosted processes occurring at higher potentials and responsible for the formation of adsorbed $\mathrm{RO}^{-}$. Moreover, TMSPi contributes to control the SEI creation by NaODFB and its growing over cycling. To the best of our knowledge, this contribution represents the first example reporting the $\mathrm{CV}$ study of the synergy between additives of a battery electrolyte. Furthermore, an evaluation of the SEI stability over time by cyclic voltammetry was proposed as method for a preliminary screening of the electrolytes. According to this approach, the new electrolyte composition herein reported proved to be very promising in NVPF/C batteries for practical applications, in strong agreement with the battery cycling tests. This patented electrolyte is presently successfully implemented in practical $18650 \mathrm{Na}_{3} \mathrm{~V}_{2}\left(\mathrm{PO}_{4}\right)_{2} \mathrm{~F}_{3} / \mathrm{C}$ cells (Figure 8). It enables excellent cycling and self-discharge performances at $55^{\circ} \mathrm{C}$, however perfection has not been fully reached. Indeed, minor remaining improvement deals with the gas release during the first cycle that we still need to minimize. A privileged direction we are being working on involves the chemical modification of the TMSPi additive.

\section{Acknowledgments}

J.-M.T. acknowledges funding from the European Research Council (ERC) (FP/2014)/ERC, Grant-Project 670116-ARPEMA. The au-

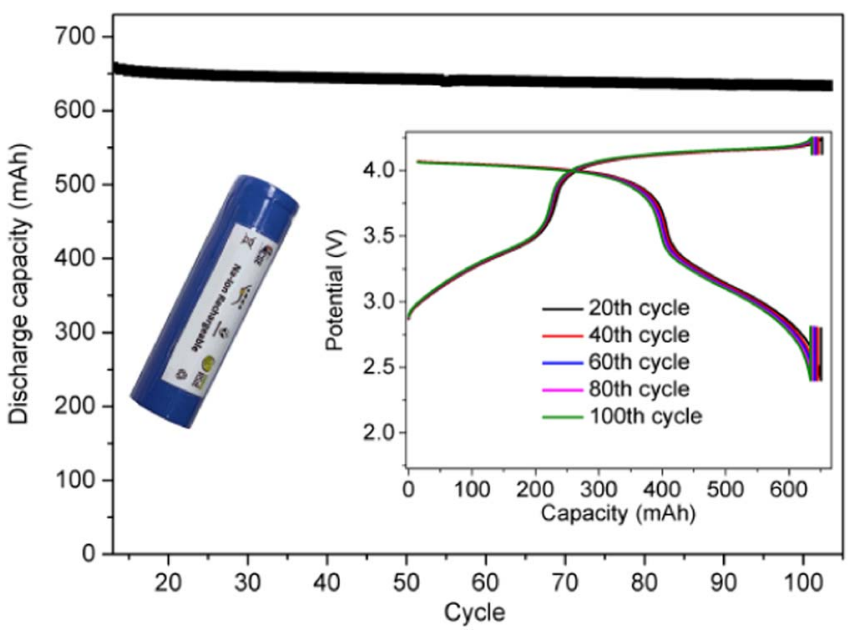

Figure 8. The cycling performances at $55^{\circ} \mathrm{C}$ of a 18650 -type $\mathrm{NVPF} / \mathrm{C}$ cell with the optimized electrolyte formulation containing VC, NaODFB and TMSPi in EC/DMC $\left(1: 1\right.$ in volume, $\left.+1 \mathrm{M} \mathrm{NaPF}_{6}\right)$. The cell was run at $55^{\circ} \mathrm{C}$ for 10 cycles before a 1-week resting time at $100 \%$ SoC and the cycles after self-discharge are shown. The voltage-capacity curves at $20^{\text {th }}, 40^{\text {th }}, 60^{\text {th }}, 80^{\text {th }}$ and $100^{\text {th }}$ cycle are shown in the inset.

thors gratefully acknowledge Dr. Grégory Gachot for the GC-MS analysis, Dr. Julien Rolland, Dr. Iona Moog for the 18650-type battery experiments and Nicolas Dubouis for fruitful discussion. There are no conflicts to declare. The optimized electrolyte formulation reported in this paper is patented; patent filing number: EP18305743, "New electrolyte composition for sodium ion battery," G. Yan, J-M. Tarascon (2018).

\section{ORCID}

Claudio Cometto (iD https://orcid.org/0000-0001-5737-9988

Guochun Yan (1D https://orcid.org/0000-0002-1892-9331

Sathiya Mariyappan (1D https://orcid.org/0000-0003-2851-5906

Jean-Marie Tarascon (D) https://orcid.org/0000-0002-7059-6845

\section{References}

1. V. Etacheri, R. Marom, R. Elazari, G. Salitra, and D. Aurbach, Energy Environ. Sci., 4, 3243 (2011).

2. M. D. Slater, D. Kim, E. Lee, and C. S. Johnson, Adv. Funct. Mater, 23, 947 (2013).

3. S. Roberts and E. Kendrick, Nanotechnol. Sci. Appl., 11, 23 (2018).

4. M. Gauthier, T. J. Carney, A. Grimaud, L. Giordano, N. Pour, H.-H. Chang, D. P. Fenning, S. F. Lux, O. Paschos, C. Bauer, F. Maglia, S. Lupart, P. Lamp, and Y. Shao-Horn, J. Phys. Chem. Lett., 6, 4653 (2015).

5. S. J. An, J. Li, C. Daniel, D. Mohanty, S. Nagpure, and D. L. Wood III, Carbon, 105, $52(2016)$.

6. J. Song, B. Xiao, Y. Lin, K. Xu, and X. Li, Adv. Energy Mater, 8, 1703082 (2018)

7. R. Mogensen, D. Brandell, and R. Younesi, ACS Energy Lett., 1, 1173 (2016).

8. D. I. Iermakova, R. Dugas, M. R. Palacín, and A. Ponrouch, J. Electrochem. Soc., 162, A7060 (2015).

9. G. Yan, D. Alves-Dalla-Corte, W. Yin, N. Madern, G. Gachot, and J.-M. Tarascon, J. Electrochem. Soc., 165, A1222 (2018)

10. G. Yan, K. Reeves, D. Foix, Z. Li, C. Cometto, S. Mariyappan, M. Salanne, and J.-M. Tarascon, Advanced Energy Materials, accepted.

11. Z. Zhang and S. S. Zhang, Eds., Rechargeable batteries: materials, technologies and new trends, p. 712, Springer, Cham Heidelberg New York Dodrecht London, (2015).

12. Y.-K. Han, J. Yoo, and T. Yim, J. Mater. Chem. A, 3, 10900 (2015).

13. S. Mai, M. Xu, X. Liao, J. Hu, H. Lin, L. Xing, Y. Liao, X. Li, and W. Li, Electrochimica Acta, 147, 565 (2014).

14. P. Peljo and H. H. Girault, Energy Environ. Sci., 11, 2306 (2018)

15. K. Abe, H. Yoshitake, T. Kitakura, T. Hattori, H. Wang, and M. Yoshio, Electrochimica Acta, 49, 4613 (2004).

16. X. Zhang, R. Kostecki, T. J. Richardson, J. K. Pugh, and P. N. Ross, J. Electrochem. Soc., 148, A1341 (2001).

17. D. Aurbach, K. Gamolsky, B. Markovsky, Y. Gofer, M. Schmidt, and U. Heider, Electrochimica Acta, 47, 1423 (2002).

18. G. Gachot, S. Grugeon, I. Jimenez-Gordon, G. G. Eshetu, S. Boyanov, A. Lecocq, G. Marlair, S. Pilard, and S. Laruelle, Anal. Methods, 6, 6120 (2014). 
19. https://www.bio-logic.net/wp-content/uploads/20120113-Application-Note-38 pdf.

20. S. Pérez-Villar, P. Lanz, H. Schneider, and P. Novák, Electrochimica Acta, 106, 506 (2013).

21. G. Zampardi, F. La Mantia, and W. Schuhmann, RSC Adv., 5, 31166 (2015).

22. M. Tang, S. Lu, and J. Newman, J. Electrochem. Soc., 159, A1775 (2012).

23. A. J. Bard and L. R. Faulkner, Electrochemical methods: fundamentals and applications, 2nd ed., p. 833, Wiley, New York, (2001).

24. C. Bommier, T. W. Surta, M. Dolgos, and X. Ji, Nano Lett., 15, 5888 (2015).

25. D. L. Maricle and W. G. Hodgson, Anal. Chem., 37, 1562 (1965).

26. Pablo. Cofre and D. T. Sawyer, Anal. Chem., 58, 1057 (1986).

27. A. D. Goolsby and D. T. Sawyer, Anal. Chem., 40, 83 (1968).

28. P. Hartmann, C. L. Bender, M. Vračar, A. K. Dürr, A. Garsuch, J. Janek, and P. Adelhelm, Nature Mater, 12, 228 (2013).

29. B. D. McCarthy, D. J. Martin, E. S. Rountree, A. C. Ullman, and J. L. Dempsey, Inorg. Chem., 53, 8350 (2014).

30. M. Moshkovich, Y. Gofer, and D. Aurbach, J. Electrochem. Soc., 148, E155 (2001).

31. D. Aurbach and E. Granot, Electrochimica Acta, 42, 697 (1997)

32. S. Komaba, T. Ishikawa, N. Yabuuchi, W. Murata, A. Ito, and Y. Ohsawa, ACS Appl. Mater. Interfaces, 3, 4165 (2011).

33. L. El Ouatani, R. Dedryvère, C. Siret, P. Biensan, S. Reynaud, P. Iratçabal, and D. Gonbeau, J. Electrochem. Soc., 156, A103 (2009)
34. M. S. Newman and R. W. Addor, J. Am. Chem. Soc., 77, 3789 (1955).

35. G. Smets and K. Hayashi, J. Polym. Sci., 29, 257 (1958).

36. X. Qi, L. Tao, H. Hahn, C. Schultz, S. Nowak, S. Röser, J. Li, I. Cekic-Laskovic, B. R. Rad, and M. Winter, RSC Adv., 6, 38342 (2016).

37. T. Yim and Y.-K. Han, ACS Appl. Mater. Interfaces, 9, 32851 (2017).

38. J. Chen, Z. Huang, C. Wang, S. H. Porter, B. Wang, W. Lie, and H.-K. Liu, Chem. Commun., 51, 9809 (2015)

39. I. Bhugun and J.-M. Savéant, Journal of Electroanalytical Chemistry, 395, 127 (1995).

40. I. Bhugun, D. Lexa, and J.-M. Savéant, J. Phys. Chem., 100, 19981 (1996).

41. C. Costentin, S. Drouet, G. Passard, M. Robert, and J.-M. Savéant, J. Am. Chem. Soc., 135, 9023 (2013).

42. M. H. V. Huynh and T. J. Meyer, Chem. Rev., 107, 5004 (2007).

43. D. J. Lee, D. Im, Y.-G. Ryu, S. Lee, J. Yoon, J. Lee, W. Choi, I. Jung, S. Lee, and S.-G. Doo, Journal of Power Sources, 243, 831 (2013).

44. T. Yim, S.-G. Woo, S. H. Lim, W. Cho, J. H. Song, Y.-K. Han, and Y.-J. Kim, J. Mater. Chem. A, 3, 6157 (2015).

45. J. Cha, J.-G. Han, J. Hwang, J. Cho, and N.-S. Choi, Journal of Power Sources, 357, 97 (2017).

46. M. L. Huggins, J. Am. Chem. Soc., 75, 4123 (1953).

47. J. B. Honeycutt and J. M. Riddle, J. Am. Chem. Soc., 83, 369 (1961).

48. K. Westman, R. Dugas, P. Jankowski, W. Wieczorek, G. Gachot, M. Morcrette, E. Irisarri, A. Ponrouch, M. R. Palacín, J.-M. Tarascon, and P. Johansson, ACS Appl. Energy Mater, 1, 2671 (2018). 